\title{
The Role of the Legal Culture as a Factor Determining Successful Legal Socialization of Future Specialists
}

\author{
Aigulden Togaibayeva ${ }^{1}$, Meiramgul Yessengulova ${ }^{2}$, Aliya Suguraliyeva ${ }^{3}$, Dinara Ramazanova ${ }^{1} \&$ Zhanargul \\ Tolebayeva ${ }^{1}$ \\ ${ }^{1}$ Department of Pedagogy and Psychology of Education, K. Zhubanov Aktobe Regional State University, \\ Republic of Kazakhstan \\ ${ }^{2}$ Department of Preschool and Special Education, K. Zhubanov Aktobe Regional State University, Republic of \\ Kazakhstan \\ ${ }^{3}$ Department of Social Pedagogy and Elementary Training, K. Zhubanov Aktobe Regional State University, \\ Republic of Kazakhstan
}

Correspondence: Aigulden Togaibayeva, A. Moldagulova avenue, 34, Aktobe, 030000, Republic of Kazakhstan.

Received: December 12, 2014 Accepted: March 7, 2015 Online Published: May 22, 2015

doi:10.5539/ass.v11n14p37

URL: http://dx.doi.org/10.5539/ass.v11n14p37

\begin{abstract}
Based on the integration of the provisions and conclusions acquired within the pedagogic science, the present article describes the relevance of formation of the legal culture of future specialists as a factor determining their successful legal socialization. The main functions, ways of development and structural components of the legal socialization have been shown.

Based on the results of the diagnostic study of legal socialization, a model of formation of legal culture, technology of formation of legal culture, criteria and tiered rates of formation of legal culture of future specialists have been provided in the present article.
\end{abstract}

Keywords: legal culture, legal socialization, components of legal culture, a model of formation of legal culture

\section{Introduction}

Students are the future of our country and this future depends on the social activity of the young generation, their conscious attitude to life. These are students who inherit an achieved level of social development, as well as implement the function of social reproduction. They are leading actors of the economic and political initiatives, whereby the further development of legal processes largely depends on the total level of legal culture of the youth in general and the success of their legal socialization.

Based on the analysis of many definitions of the concept of legal culture, it can be concluded that the legal culture (hereinafter - LC) can be regarded as a kind of general culture; wherein it is composed of values that are related to legal reality. At the same time LC must include only relatively progressive, socially useful and valuable components of legal phenomena. In this case, LC includes the results and methods of human activity, it manifests in the human mentality, as well as in normative standards of their behavior (Salnikov \& Romashov, 2004).

LC is better defined as a qualitative state of social reality in the sphere of law, which is expressed in a certain level of improvement of legislation, law enforcement, legal awareness of society members, the level of freedom of their behavior and responsible cooperation between the state and its citizens, which has a positive impact on the development of the society and the conditions of its existence.

An individual LC as a part of the culture of a person lies in a rather high level of legal knowledge and skills, as well as in the development of those personality traits that allow to achieve the fullest realization in the legal and social-oriented spheres (Teplyashin, 2002)

At the same time, we assume that LC has a direct impact on the personality, as a leading factor in the process of legal socialization.

LC performs various functions having a direct impact on the process of successful legal socialization (hereinafter - LS) of a person. First of all, LC is the most important means of constructing a certain type of legal personality. 
Legal rules developed in the community and acquired by an individual, have a direct impact on the LS process. LC constructs a model of individual legal behavior, that leads to the formation of legal awareness and legal activity, as constituting components of legal socialization of a person.

According to Tumanov V. A., LS means the participation of an individual in social life, based on the assimilation of legal culture of the society, as well as on the formation of his/her legal awareness (Tumanov, 2003).

Thus, the special significance of the LC role is that when implementing LS an individual takes his/her own social and legal role of the subject of social relations in which LS leads to the formation of motivation, providing not only lawful behavior of an individual, but also his/her social and legal activity.

In his study Agranat D. L. presented LS as a process during which, on the one hand, the formation of normative representations of the individual, his/her assimilation of legal values and norms, on the other hand, the individual develops skills of using standards of behavior legally acceptable in everyday life (Agranat, 2008).

LS of a person is one of the most important factors of stabilization of the society. Being a part in the life of each of the social groups, it not only has an impact on the mental and moral sphere of life, but also leads to strengthening of the society in political, economic and cultural spheres. In our opinion, this is a manifestation of the stabilizing function of LS.

The integrative function of LS, in its turn, is no less important, as it provides an opportunity to carry out the synthesis of LS and other social and legal phenomena, i.e. their unity and co-relation ensuring the functioning of the legal processes. And finally, the determining function of legal socialization is that the presence of a particular social doctrine of LS is an indicator of the level of legal social development (Stolyarenko, 2011).

According to Zhigulin A. A. (2012), the main ways of LS development of future specialists are as follows:

First, a passive way, which is characterized by spontaneous involvement of future specialists into the legal sphere, the LS development in the absence of specific targeted programs aimed at its formation. This leads to the gradual development of legal socialization, increasing the likelihood of a steady process, but stretching the time frame;

Second, an active way, involving the purposeful activity of future specialists on LS development.

Third, a comprehensive way, which is based on the creation of certain legal and pedagogical conditions, combined with the activity of future specialists, as well as the implementation of targeted programs in training practice.

Kulikova A. V. marked out several types of future specialists' LS:

1. in training process through the acquisition of general legal knowledge and mastering legal rules;

2. through the experience by understanding the experience of others and own mistakes and actions made;

3. symbolic $L S$, the essence of which consists in the formation of own concepts and ideas of an individual on laws, rules and their application.

The author assumes that training and symbolic socialization are most important for successful LS of future specialists. In this case, the legal knowledge is acquired on courses of legal studies provided in the vast majority of non-legal major disciplines. Consideration of basic legal concepts on these courses, as well as foundations of various law branches, being an integral part of the life of each citizen, is a prerequisite for successful legal socialization (Kulikova, 2007).

According to foreign authors, LS is formed in the process of legal education and training (Hiller, 2013). Legal education is an essential part of socialization of personality and a prerequisite for his/her successful functioning in society (Roberts, 2012). Legal knowledge leads to an increase in civil social activity, correct perception of legal phenomena, conscious following of laws. Legal knowledge also allows us to see beyond the limits and prohibitions. (Licht, 2007).

Legal education of future specialists is the process of mastering legal knowledge and skills that leads to an increase in the legal competence, and, as a consequence, an increase in the LS level.

Legal education of future specialists is a systematic activity, carried out both by the state and society as a whole, and individual citizens, aimed at formation of legal awareness and moral and legal standards ensuring adherence to legal standards and leading to the formation of active life position of an individual in the legal sphere (Bayniyazov, 1998). 
In this regard, the underestimation of the importance of studying law in the process of professional training of future specialists can have negative consequences, as it makes the graduate vulnerable and complicates his/her adaptation to the future professional activity (Evdokimov \& Kalandarishvili, 2006).

The period of study at the university is a turning point in the LS process. During this period, the sustainable "I"-image of a person and all its aspects are being developed. The development of legal consciousness of the personality and, as a consequence, - the development of legal " $I$ ", signifying the degree of involvement of the subject in the system of legal relations, awareness and value adoption of legal rules, law-abiding behavior, value attitude to other people and, consequently, to the person's rights are important and integral components of the self-consciousness of this period.

The high level of all these indicators can show the degree of social inclusion an individual in the process of life of the whole society. (Kaminskaya \& Ratinov, 1974; Makhrova, 2012).

The main result of LC and LS is in the final formation of the legal activity of a person. In this case, both phenomena discussed above are considered as necessary and strategic components of the socio-positive behavior of an individual, since the formation and increase of LC of the society occurs when its members assimilate and maintain traditional norms and standards of behavior typical for the social and legal environment, according to which an individual has a formed set of qualities necessary for successful adaptation in the social and legal environment, as well as for the implementation of socio-positive behavior and performance of certain functions. A person, who does not have these properties, when incorporated into the legal space, often has difficulties with the ability to adapt to the requirements put forward by the society, as well as to protect their rights and effectively defend own interests in social and legal spheres of society (Zubok \& Chuprov, 2006).

Thus, LS is an essential element of the overall process of inclusion of an individual in public relations. First of all, it includes the process of assimilation of the society LC, as well as the active comprehension of the existing legal reality, continuing development of legal awareness and the formation of LC of an individual. The formation of an individual having developed positive LC becomes the main content of LS process.

On the basis of this definition of LS, its structure can be divided into three main components: cognitive, behavioral, personality ones.

The cognitive component of LS includes the development of basic legal facts and concepts, law terminologies, the essence of legislation.

Behavioral component of LS is the ability to practice the learned legal knowledge, carry out own behavior in accordance with the legislation, show a legal activity under different circumstances of professional activities.

The personal component of LS demonstrates emotionally-sensual relation of an individual to the legal rules and phenomena, violation of human rights, as well as motivation to legal behavior.

\section{Methods}

Based on the three-component composition of LS, we have carried out a diagnostic study of LS components of future specialists. In the present study we started with the assumption that LS is a system which components are closely linked, and separating each one from the other would be rather difficult in the sense that, for example, the personal component cannot be studied in isolation from the cognitive and behavioral components, since it mediates the manifestations of other components. For example, a person's attitude is based on certain knowledge and acquired ways of behavior and, at the same time, it determines them. As for the behavioral component of LS, we know that the activities and human behavior are determined by cognitive schemes and the system of motives, roughly speaking, the activities are managed by the mind and emotions. The cognitive component also does not exist by itself, because the level of knowledge and awareness are defined in some way by a positive and value attitude to the information that comes from the environment.

The first stage of the diagnostic study was to conduct diagnostic methods of the level of knowledge of the respondents in jurisprudence (the cognitive component of LS). For this we used the tests, specially designed for the course program "Jurisprudence".

At the second stage we studied the behavioral component of LS, using a block of the tasks from the workshop on the course "Jurisprudence". The following tasks have been proposed:

"Your friend asked the legal advice centre for clarification about the possible administrative penalty, which he may incur for the offense. Should the court take into account this clarification when assigning your friend penalty for this offense? Give a reasoned response. Will something change if the administrative penalty is imposed not by the court, but by the customs authorities? " 
"When meeting a citizen complained to his friend on a bad day: first, on the way to work he was fined by the traffic police for violation of the traffic rules, and then he received a reprimand for being late to work. What responsibilities were placed upon him?"

At the third stage, we studied the personality component of LS, using standardized diagnostic methods. We decided to try to investigate the attitude of the respondents to the social sphere, reflected in the level of empathy, the ability to self-control and impulsivity, considered as a trait, opposite such strong-willed qualities as ambition and insistence. For this purpose, we used the methods of diagnosing the level of empathic abilities, developed by Boyko V. V., the locus of subjective control and impulsivity by using the test-questionnaire of Losenkov V. A.

We hypothesized that the personal component is systemically important in the system of LS. When we talk about the fact that some component is systemically important, we mean its mediating character for all other system components. This means that an influence or a change in this component shall also change, or may even restructure the remaining components. Theoretical and practical studies of the problem of LS evidence in favor of this provision.

\section{Results}

Already being tested some respondents had problems of giving correct answers related to misunderstanding or lack of knowledge of the terms or provisions of the course "Jurisprudence". But the situations that attracted more attention, occurred when the respondent could not give the correct answer, if a certain degree of awareness and orientation in the legislation was required. We paid attention to these situations as a high level of development of the cognitive component of LS is not limited to a certain amount of knowledge.

During the study we also noticed everything the respondents said, the form of answers to the experimenter's questions about their attitude to the factors of a proposed situation.

According to the results of testing of legal knowledge and correctness of solving the legal situations, the majority of participants had an average level.

Mathematical processing of study results confirmed the presence of significant links between cognitive and behavioral components of LS, on the one hand, and the presence of empathic abilities, high internality and low impulsivity, on the other hand, provided that a rate of internality (locus of control) has the greatest impact on cognitive and behavioral components of LS. The next important factor is impulsivity of personality.

Thus, the results of our study showed the presence of a direct effect of the personal component of LS of the level of legal knowledge (cognitive component of LS) and the level of the correct solution of a legal situation (behavioral component of LS).

\section{Discussion}

The results of the study showed the need for more effective actions on the development of legal socialization of future specialists by way of forming their legal culture. In this connection, on the basis of previous studies (Lukash, 2011; Nemytina, 2008; Chikeeva, 1992), we developed a model of formation of the legal culture of future specialists presented in Figure 1.

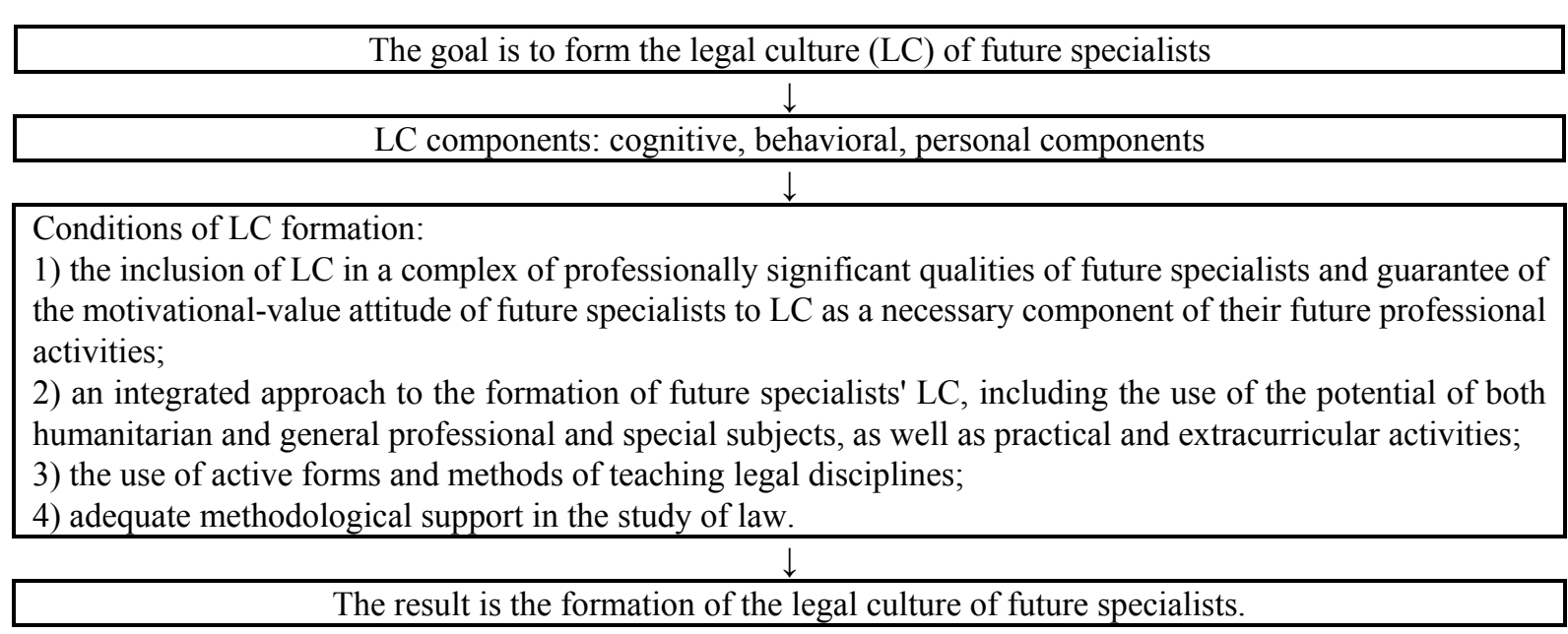

Figure 1. The model of formation of the legal culture of future specialists 
This model provides the activation of promising possibilities of legal disciplines, consideration of their specific character, updating the system "teacher - student", selection of the content of the received information in order to develop mental abilities and expand the outlook of students, formation of their professional motivation, legal, moral and value principles, orientation for independent learning activities.

The model of formation of future specialists' LC consists of four units:

1) A target unit, reflecting the planned training results. The purpose of this model is to form LC as a component of professional culture of future specialists;

2) An informative unit, which includes cognitive, behavioral and personal components of LC. Formation of future specialists' LC is considered in this case as a process that is aimed at the student for the purpose of his/her development as a professional. Therefore, the content of this process should consist not only in obtaining specific knowledge in the sphere of law, but also in the formation of motivation, the development of future specialists' interest in matters of law in general, training to apply their knowledge in practice, the implementation of the value-conscious attitude to the chosen profession and its legal regulation;

3) An organization unit, which indicates the number of pedagogical conditions, through the implementation of which the efficiency of the formation of future specialists' LC gets significantly increased;

4) An effective unit, showing the effectiveness of the implementation of the process of the formation process of future specialists' LC, the results obtained in accordance with the intended purpose. An assessment of the progress in the implementation of this model is carried out by means of diagnosing the level of formation of LC components of future specialists.

In the process of the LC formation future specialists may have the difficulties connected with the following:

- a different level of training and formation of future specialists' LC;

- insufficient legal knowledge and awareness of the need for LC formation;

- the negative reaction of students to the proposed problem tasks and situations, to the mistakes made in solving them;

- the passivity of some of future specialists;

- the occurrence of interpersonal conflicts among future specialists;

- monopolization of the voting right by any of them in solving group tasks;

- difficulties in formulating conclusions and summarizing;

- disagreement of some students with the results of LC formation.

Thus, the proposed model for the formation of future specialists' LC has a certain structure, aimed at improving the legal training of future specialists and allows more clearly outline the process of training of future specialists for future professional activities and its legal regulation.

The model of the formation of future specialists' LC served as the basis for the practical formation of future specialists' LC in the educational process. Technology of formation of future specialists' LC is shown in Figure 2.

At the same time, according to Kalandarishvili Z. N. (Kalandarishvili, 2010), the personal component of LS of future specialists can be formed as a result of discussions on issues of law and law enforcement, as well as in the implementation of creative tasks in the group. The author assumes that the goal of formation of the personal component of LS is "the formation of legal opinion, ethical and legal systems", when the integration of students' acquired knowledge and personal experience occurs. Performance indicators of the formation of the personal component of LS are learning adequate legal views, opinions and attitudes, as well as the emergence of the need to actively participate in law enforcement and law-making processes.

For the formation of cognitive-behavioral component of LS the solution of problem tasks and situations, aimed at the development of adequate legal attitude, can be used. In this case, students provide an objective assessment of the current problematic situation which should be close to the realities of their future careers. As a result the experience in specific law-making and law enforcement activities of future specialists in their chosen profession shall be formed. The effectiveness of formation of the cognitive-behavioral component of LS shall be confirmed by the students' creative approach to work and making adequate legal solutions.

In general, performance indicators of formation of all LS components should be positive changes in the level of future specialists' LS, their ability to provide an adequate assessment of themselves and their group mates. 
Understanding the need to increase the LC level by a teacher and future specialists, reflection
The analysis of the leading theoretical ideas and methodological foundations of the formation of future specialists' LC

$\downarrow$

Diagnostics of formation of future specialists' LC

$\downarrow$

Setting goals - definition of personally important goals of formation of future specialists' LC

$\downarrow$

Creating the conditions for implementing the goals:

1. The increase in professional orientation in the content of legal disciplines and coordination of training programs;

2. The use of the learning process of problem-oriented situations and tasks that are relevant to the real professional activity of future specialists or close to it;

3. The optimization of formation of future specialists' legal awareness and legal activity;

4. The improvement of the quality of the legal and pedagogical training of teaching staff.

$\downarrow$

The organization of educational process

The activities of teachers in the lectures, aimed at The activity of future specialists, aimed at managing the process of increasing the level of self-organization, self-development, correction of future specialists' LC personal attitudes and legal values and orientations

Diagnosis of the educational process

$\downarrow$

Assessment and analysis of results on the formation of future specialists' LC, the correction of results, the conclusions on the work done

Figure 2. Technology of formation of future specialists' LC

In order to assess the level of formation of future specialists' LC the following criteria and indicators of LC formation can be used (Table 1).

Table 1. Criteria and indicators of formation of future specialists' LC

Criteria of formation of Indicators of criteria of formation of future specialists LC future specialists' LC

The success rate of Awareness of the conditions of a legal situation.

solving problem tasks in The analysis of the legal problem and situation.

the course of legal activity The ability to relate the legal problem and situation with specific rules.

The ability to give the correct legal decision of the legal problem and situation.

An explanation presented as a logical construct a chain of arguments and counterarguments.

The statement of personal legal position regarding the legal problem and situation.

Forecasting the consequences of the proposed legal solution to the legal problem and situation under consideration.

Orientation when Application of the legal knowledge in solving legal problems.

choosing tools for Selection of a rational solution of the legal problem.

conducting legal activities Objectivity in the assessment of legal reality.

Based on the criteria of LC formation of future specialists we can identify and justify the following five levels of LC formation: high, above average, average, below average, low. 
A high level of LC can be identified by a good knowledge of legal disciplines, an interest in the study of the legal validity and legal activities, legal activity, the adequacy of the choice of legal actions in different situations. The future specialists with the above-average level of LC formation can have some gaps in the knowledge of the law basics.

Future specialists with an average level of LC are characterized by an interest in certain events of law enforcement practice, lack of knowledge on the rights and responsibilities of citizens, showing legal activity only in cases when unlawful acts invade the area of interests of the individual.

Future specialists with a below-average level of LC is characterized by passivity of their legal position, indifference to legal activity, low level of knowledge on legal disciplines, and as a result, they make incorrect or inadequate legal solutions.

A low level of LC is characterized by indifference to legal activities, passivity of one's legal position, lack of knowledge of fundamentals of legislation, making inadequate legal solutions.

\section{Conclusion}

Summing up the results of the study, we can say that an exhaustive analysis of the role of legal culture as a factor determining successful legal socialization of future specialists provides an opportunity to demonstrate features of these mechanisms, reveal the essential content of formation of the legal culture and legal socialization in their indissoluble unity, that is of particular importance for the modern Russian society.

As is known, one of the primary needs of an individual is to strive for associating oneself with a particular set of social values and rules in order to be able to correctly assess one's own and other people's behavior. And only a high enough level of legal culture and successful legal socialization allow a person to carry out effective orientation in social and legal environment, implement legitimate ways of one's own behavior and wait for positive law-abiding ways of activities on the part of surrounding society members.

Thus, two such fundamental public legal phenomena as legal culture and legal socialization exist in close correlation and in the course of functioning these phenomena cannot exist in modern society in the absence of one another.

Only an adequate level of legal culture enables an individual to successfully develop the necessary level of own legal socialization. At the same time, this adequate level of legal socialization shall be achieved by an individual in all three its main components: cognitive, behavioral and personal. In the case when one of the components will be formed insufficiently, the cumulative process of legal socialization can go in a wrong direction.

\section{References}

Agranat, D. L. (2008). Regulatory and real legal socialization of students - future lawyers. State and law, 4.

Bayniyazov, R. S. (1998). Legal consciousness: Psychological aspects. Jurisprudence, 3, 16-21.

Chikeeva, Z. Ch. (1992). Formation of legal culture of students in modern conditions. Moscow: RGPU.

Evdokimov, A. S., \& Kalandarishvili, Z. N. (2006). Legal culture of a person in the mechanism of the development of modern constitutional state. Philosophy and Law, Saint-Petersburg, 62-67.

Hiller, V., \& Recoules, M. (2013, June). Changes in divorce patterns: Culture and Law. International Review of Law and Economics, 34, 77-87. http://dx.doi.org/10.1016/j.irle.2013.01.002

Kalandarishvili, Z. N. (2010). An impact of legal socialization on the process of constructing the legal culture of an individual in contemporary Russian society. A.I. Herzen Russian State Pedagogical University Bulletin, 137.

Kaminskaya, V. I., \& Ratinov, A. R. (1974). Legal consciousness as an element of legal culture. Legal culture and issues of legal education, Moscow.

Kulikova, A. V. (2007). The formation of law sociology in higher education system as one of the directions of legal socialization of students. Sociology and Social Work. N.I. Lobachevsky Nizhny Novgorod University Bulletin, 1(6), 40-43.

Licht, A. N., Goldschmidt, Ch., \& Schwartz, S. H. (2007, December). Culture rules: The foundations of legal rules and other norms of governance. Comparative Economics Journal, 35(4), 659-688. http://dx.doi.org/10.1016/j.jce.2007.09.001

Lukash, O. A. (2011, October). The model of formation of legal competence of culture college students. Pedagogy: Traditions and Innovation: Materials of the international scientific conference, Chelyabinsk, 2, 
49-52.

Makhrova, E. I. (2012). On the concept of legal socialization of students as a pedagogical problem. Orenburg State University Bulletin, 4(140).

Nemytina, M. V. (2008). Effective models of law teaching. Materials of the All-Russian Scientific and Methodology Conference "Modern forms and methods of law teaching", Saratov, 13-18.

Roberts, P. (2012, September, 27). Renegotiating forensic cultures: Between law, science and criminal justice. Studies in History and Philosophy of Science, Part C: Studies in History and Philosophy of Biological and Biomedical Sciences, In Press, Corrected Proof.

Salnikov, V. P., \& Romashov, R. A. (2004). Legal culture as a factor in the stabilization of the modern Russian society. Law as a cultural phenomenon, Saint-Petersburg, 47-58.

Shilova, M. I. (2000). Construction of the educational process and environment of education of the new generation of Russian citizens (the scientific content of the project). KSPU Scientific Annual. Krasnoyarsk: RIO KSPU.

Stolyarenko, D. V. (2011). Legal socialization: a socio-philosophical aspect. Theory and practice of social development, 2 .

Teplyashin, I. V. (2002). Formation of the Russian legal statehood and legal activity of citizens. Russian Law Journal, $1,38$.

Tumanov, V. A. (2003). Legal nihilism in the historical and ideological perspective. State and Law, 8.

Zhigulin, A. A. (2012). Legal culture of students as a social phenomenon. Psychology, sociology and pedagogy. Retrieved March, 2012, from http://psychology.snauka.ru/2012/03/247

Zubok, Y. A., \& Chuprov, V. I. (2006). Legal culture of the youth in the perspective of transformation strategies. Sotsis, 6 .

\section{Copyrights}

Copyright for this article is retained by the author(s), with first publication rights granted to the journal.

This is an open-access article distributed under the terms and conditions of the Creative Commons Attribution license (http://creativecommons.org/licenses/by/3.0/). 